\title{
Numerical Treatment For MHD Axisymmetric Rotating Bodewadt Rheology Under Ohmic Heating And Viscous Dissipation Effects
}

\section{Awais}

COMSATS University Islamabad, Attock Campus

Marium Bibi

COMSATS University Islamabad, Attock Campus

Aamir Ali ( $\square$ aamir_ali@cuiatk.edu.pk )

COMSATS University Islamabad, Attock Campus

\section{Research Article}

Keywords: Bodewadt flow, Magnetic field, Heat transfer, Joule heating, Variable viscosity, Viscous dissipation, Wall suction, Internal heat generation/absorption, Similarity solution,

Posted Date: February 24th, 2022

DOI: https://doi.org/10.21203/rs.3.rs-1364435/v1

License: (9) This work is licensed under a Creative Commons Attribution 4.0 International License. Read Full License 


\title{
Numerical Treatment for MHD Axisymmetric Rotating Bodewadt Rheology under Ohmic Heating and Viscous Dissipation Effects
}

\author{
M. Awais ${ }^{\text {a }}$, Marium Bibi ${ }^{\text {a }}$ and Aamir Ali ${ }^{\text {a }}$ * \\ aDepartment of Mathematics, COMSATS University Islamabad, Attock Campus, Kamra Road, \\ Attock, 43600, Pakistan. \\ *Email: aamir_ali@cuiatk.edu.pk, aamir_ali@ ciit-attock.edu.pk
}

\begin{abstract}
The present research manuscript is intended to scrutinize the impacts of heat transfer in a Bodewadt flow above a penetrable disk numerically. The repercussions of internal heat generation and absorption, viscous dissipation, magnetic field, joule heating accompanying with variable properties of the fluid are also inspected as well. Within the recent past, multifarious scientists have prophesied that physically compatible solution of heat energy equation in a Bodewadt flow exist only when the disk is permeable. The final problem contains the variable $\theta_{e}$ which estimates the rate of dependence of fluid viscosity on the temperature. We transmuted the governing equations of heat transfer (accompanied by variable properties) and motion of fluid in to self-similar non-dimensional differential equations by utilizing the Von-Karman variables. The major result of this research study is that the velocity \& temperature of the fluid surrounding the disk are substantially altered by taking numerous values of parameter of variable viscosity $\theta_{e}$. Command of NDSolve in Mathematica software on the basis of Adams Bashforth method is employed to obtain numerical statistics from suggested mathematical model. Numerical results for velocity constituents $(\mathrm{F}, \mathrm{G}, \mathrm{H})$ and temperature curves $(\boldsymbol{\theta})$ for distinct emerging parameters are illustrated graphically. Additionally, the values of co-efficient of skin friction and nusselt number are calculated for different emerging parameters and their behavior are exposed physically with the assistance of tables and bar charts.
\end{abstract}

Keywords: Bodewadt flow; Magnetic field; Heat transfer; Joule heating; Variable viscosity; Viscous dissipation; Wall suction; Internal heat generation/absorption; Similarity solution;

\section{Introduction}

Three-dimensional flow problems produced by virtue of a rotating viscous fluid are experienced in a number of engineering-relevant, product-designing, industrial and scientific products and 
procedures for instance centrifuges, viscometers, jet engines, turbines, mixing in chemical chambers, vacuum cleaners, disk drives of computers and turbo-machinery etc. A classicistic problem in the field of fluid mechanics is the problem of fluid flow that is generated by a disk which possesses large diameter and is revolving about it's origin under the influences of constant angular velocity. Many years ago, Von-Karman [1] composed and resolved this problem. Anyone doesn't visualized an accurate circular flow close to the disk in this fluid problem since there is not applied pressure gradient that supplied the radial component of acceleration inwards and, as a consequence, fluid scrolled outside. Von-Karman [1] who was capable to transform the system of Navier-Stoke's equation into a set of ordinary differential equations with the assistance of appropriate similarity transformations. Cochran [2] noted some imprecisions in the solution of Von-Karman's problem and then developed an asymptotic solution of that problem. Ackroyd [3] elongated the problem of Von-Karman by accounting the impacts of injection/suction and illustrated series solution that comprises of the exponentially decomposing expressions. A similar problem is originated when the fluid revolves under the influences of constant angular velocity over a motionless plane is second fascinating problem. On the contrary, the fluid particles close to the disk moves in the direction of axis of rotation since it's circumferential constituent of velocity is decelerated under the similar pressure gradient. Tabassum and Mustafa [4] modeled numerically the heat transfer and partial slip flow of reiner-rivlin non-newtonian fluid generated by a revolving disk. A distinctive illustration made by researchers in this regard is given in references [5-10]. Contrary to Von-Karman [1] problem's, Bodewadt [11] demonstrated that problem in 1940 by constructing boundary layer conditions. In Bodewadt's flow, fluid particles around the disk under the impact of radial pressure gradient directed to proceed inside towards the rotational axis where fluid is in the condition of stiff-body rotation. Bodewadt flow is also monitored in a tea cup when rotation in the fluid is urged by continuously stirring and then left the flow of fluid for a little while. Bodewadt flow is additionally perceived further in many procedures such as hurricanes, foodprocessing industries, tornadoes, turbo-machinery and chemical mixing chambers etc. Sahoo et al. [12] modeled numerically the heat transfer and steady revolving flow of a Reiner-Rivlin fluid using shooting and finite difference method. Sahoo et al. [13] obtained numerical solution of viscous fluid for steady Bodewadt flow using finite difference and keller-box method. Rafiq et al. [14] examined numerical assessment of nanofluid for Bodewadt slip flow above a convectively heated permeable disk. Muhammad et al. [15] formulated entropy production in three-dimensional 
Bodewadt flow of nanofluid over an infinite stationary disk. Some recent attempts related to Bodewadt flow can be seen in Refs. [16-27].

Heat transfer is the field of thermal engineering which deals with the use, generation, conversion and exchange of thermal energy between physical systems (i.e: heat energy). Transfer of heat is categorized within various mechanisms such as radiation, convection and conduction. Transfer of heat has broad range of applications in climate engineering, architecture, industries of chemical process, greenhouse effect and heat transfer in the body of human beings. There is an immense impact of temperature gradients on characteristics of fluid. Particularly, there is a direct relationship between temperature and viscosity in gases while an inverse relationship between temperature and viscosity is in liquids. Variable characteristics of fluid flows are often perceived in applications associated with aerodynamics \& aero-acoustics. Takhar et al. [28] examined the impacts of fluid properties that depends upon temperature on boundary layer flow above a continuous moving surface. They considered two cases, namely, variable fluid viscosity and constant fluid properties. Salahuddin et al. [29] examined the rotating behavior of $2^{\text {nd }}$-grade fluid with mass \& heat transfer effects between two parallel plates. Ahmed et al. [30] numerically modeled the unsteady MHD flow and heat transfer with variable viscosity of nanofluid in carbon nanotubes over a shrinking porous surface. Rafiq et al. [31] formulated the impacts of heat transfer in fluid flow produced by a revolving permeable disk with variable characteristics of fluid. Several attempts in this regime has been made by investigators includes [32-40].

The heat which is produced due to the flow of an electric current through a conductor is called joule heating, also known as ohmic heating. Joule heating have a wide range of applications in our daily life such as glowing of filament of an incandescent light bulb, electrical fuses, hotplate of electrical tabletop etc. Viscous dissipation is an irreversible procedure in which the work is done by a fluid on adjoining layers owing to the action of shear forces is converted into heat. Impacts of viscous dissipation plays a crucial role in natural convection in numerous devices that are subjected to large variations of gravitational force or which operate at high speed. Jawad et al. [41] discussed the analysis of transfer of heat and entropy generation in MHD flow of carbon nanotubes with the impacts of viscous dissipation and thermal radiation. Afridi et al. [42] described the chaos analysis in stagnation point flow with MHD, ohmic heating \& fluid friction impact. Entropy analysis in MHD nanofluid due to a heated stretching surface with viscous dissipation \& radiation 
are analyzed by Sithole et al. [43]. Zubair et al. [44] investigated the entropy generation optimization in three-dimensional MHD flow between two parallel rotating plates of casson nanofluid with viscous dissipation \& ohmic heating effects. The latest investigations in this regime include studies [45-52].

Magnetohydrodynamics describe the study of motion of electrically conducting fluid (e.g. liquid metals and plasmas) in the presence of a magnetic field. The key hypothesis behind magnetohydrodynamic is that magnetic fields can generate current in a moving conductive fluid, which sequentially produce a force on the fluid and also alter the magnetic field itself. MHD have broad variety of applications in the field of Astrophysics, Geophysics, Engineering and Magnetic drug targeting. Shah et al. [53] analyzed the radiative effect radiation in magnetohydrodynamic casson nanofluid flow along with entropy generation and chemical reactions above a nonlinearily stretching sheet. Awais et al. [54] explained the mathematical modeling of prandtl MHD melted fluid flow towards an inclined cylindrical surface. Khan et al. [55] explained the entropy optimization rate in magnetohydrodynamic flow of viscous liquids with chemical reactions due to curved stretchable surface. Alreshidi et al. [56] discussed the thermophoresis effects and brownian movement in an incompressible and time independent flow of MHD nanofluid due to permeable revolving disk. Bibi et al. [57] presented theoretical analysis of magnetohydrodynamic carreau fluid above a revolving disk with the aid of von-karman transformations. Some remarkable applications regarding magnetohydrodynamics are cited here [58-62].

Inspired by the recent work of Rafiq et al. [63] and Andersson and Rahman [17], we strive to formulate influences of heat transfer in a Bodewadt flow along with the impacts of joule heating, wall suction, internal heat generation and absorption, magnetic field and viscous dissipation when properties of fluids that are dependent on the temperature are considered. Our mathematical paradigm includes the influences of thermal conductivity and viscosity that are dependent on temperature of the fluid. Transformed governing mathematical model of equations will be examined numerically by implementing command of NDSolve in Mathematica software on the basis of Adams Bashforth method. Consequences of developing parameters will be described by plotting graphs, bar charts and displaying outcomes in the tables.

\section{Mathematical formulation of problem:}

Assume that a viscous fluid flow having variable characteristics of fluid above a penetrable disk 
as depicted in Fig. 1 across origin. The disk is rotating around vertical axis with uniform angular velocity $\omega$. The components of velocity $\left(V_{r}, V_{\varphi}, V_{z}\right)$ are taken in the direction of cylindrical coordinates $(r, \phi, z)$. The temperature of disk is supposed constant on $T_{w}$ while the temperature of exterior flow is considered as $T_{\infty}$. A uniform magnetic field of strength $B_{0}$ is functional along the z-direction while the induced magnetic field is presumed to be negligible.

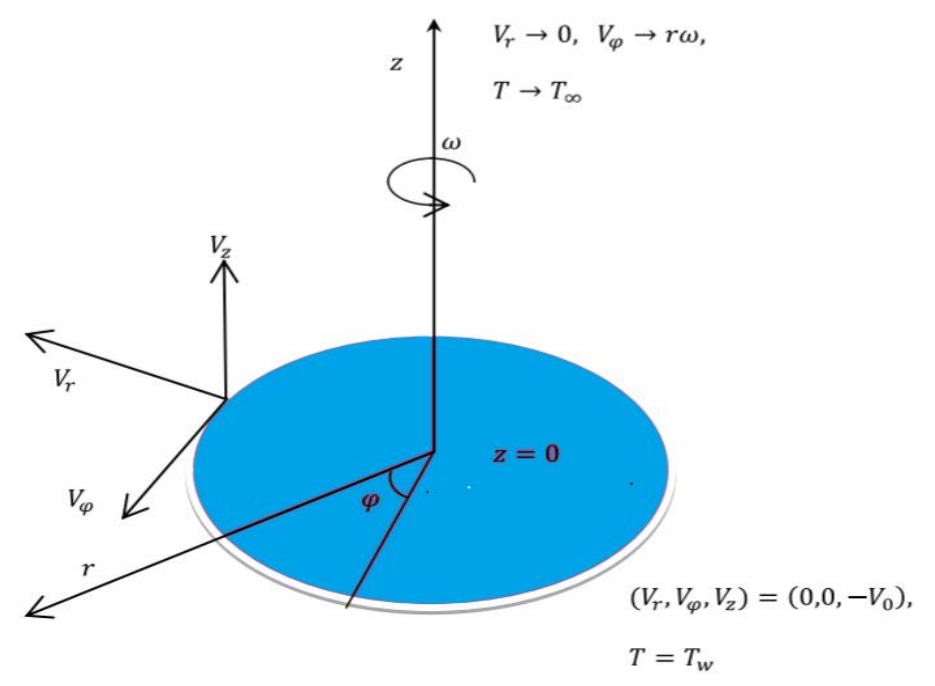

Fig. 1: Physical configuration and coordinate system

The equation of motion, Navier- Stoke's equation and thermal energy equation with internal heat generation and absorption, viscous dissipation \& ohmic heating takes the form as mentioned below:

\begin{tabular}{|c|c|}
\hline$\frac{\partial\left(r V_{r}\right)}{\partial r}+\frac{\partial\left(r V_{z}\right)}{\partial z}=0$, & (1) \\
\hline$\rho\left(V_{r} \frac{\partial V_{r}}{\partial r}+V_{z} \frac{\partial V_{r}}{\partial z}-\frac{V_{\varphi}^{2}}{r}\right)+\sigma B_{0}^{2} V_{r}=-\frac{\partial p}{\partial r}+\frac{\partial \tau_{r r}}{\partial r}+\frac{\partial \tau_{r z}}{\partial z}+\frac{\tau_{r r}-\tau_{\varphi \varphi}}{r}$, & (2) \\
\hline$\rho\left(V_{r} \frac{\partial V_{\varphi}}{\partial r}+V_{z} \frac{\partial V_{\varphi}}{\partial z}+\frac{V_{r} V_{\varphi}}{r}\right)+\sigma B_{0}^{2} V_{\varphi}=\frac{1}{r^{2}} \frac{\partial}{\partial r}\left(r^{2} \tau_{r \varphi}\right)+\frac{\partial}{\partial z} \tau_{z \varphi}+\frac{\tau_{r \varphi}-\tau_{\varphi r}}{r}$, & (3) \\
\hline$\rho\left(V_{r} \frac{\partial V_{z}}{\partial r}+V_{z} \frac{\partial V_{z}}{\partial z}\right)=\frac{1}{r} \frac{\partial}{\partial r}\left(r \tau_{r z}\right)+\frac{\partial}{\partial z} \tau_{z z}$ & (4) \\
\hline
\end{tabular}




$$
\begin{aligned}
& \rho c_{P}\left(V_{r} \frac{\partial T}{\partial r}+V_{z} \frac{\partial T}{\partial z}\right)=-\nabla \cdot[-k(T) \cdot \nabla T]+\sigma B_{0}^{2}\left(V_{r}^{2}+V_{\varphi}^{2}\right)+Q^{*}\left(T-T_{\infty}\right) \\
& +\mu\left[2\left\{\left(\frac{\partial V_{r}}{\partial r}\right)^{2}+\left(\frac{V_{r}}{r}\right)^{2}+\left(\frac{\partial V_{z}}{\partial z}\right)^{2}\right\}+\left(\frac{\partial V_{\varphi}}{\partial z}\right)^{2}+\left(\frac{\partial V_{r}}{\partial z}+\frac{\partial V_{z}}{\partial r}\right)^{2}+\left(r \frac{\partial}{\partial r}\left(\frac{V_{\varphi}}{r}\right)\right)^{2}\right],
\end{aligned}
$$

$\operatorname{Here}\left(V_{r}, V_{\phi}\right.$ and $\left.V_{z}\right)$ in the above equations represents the constituents of fluid velocity in the radial, tangential and axial directions, $(\rho)$ indicates the fluid density, $\left(C_{p}\right)$ indicates the specific heat capacity, $\left(B_{0}\right)$ represents the magnetic field intensity, $k(T)$ stands for thermal conductivity, $(\mu)$ indicates the dynamic viscosity, $(T)$ denotes the temperature of fluid, $(\sigma)$ represents the electrical conductivity, $\left(T_{\infty}\right)$ represents the free stream temperature and $\left(Q^{*}\right)$ stands for coefficient of heat generation/absorption . The stress tensor components are given as:

$$
\begin{aligned}
& \tau_{r r}=\mu\left(2 \frac{\partial V_{r}}{\partial r}\right), \tau_{\varphi \varphi}=\mu\left(\frac{2 V_{r}}{r}\right), \tau_{z z}=\mu\left(2 \frac{\partial V_{z}}{\partial z}\right), \\
& \tau_{\varphi z}=\tau_{z \varphi}=\mu\left(\frac{\partial V_{\varphi}}{\partial z}\right), \tau_{r z}=\tau_{z r}=\mu\left(\frac{\partial V_{r}}{\partial z}+\frac{\partial V_{z}}{\partial r}\right), \tau_{r \varphi}=\tau_{\varphi r}=\mu\left(\frac{\partial V_{\varphi}}{\partial r}-\frac{V_{\varphi}}{r}\right),
\end{aligned}
$$

We presume that viscosity $(\mu)$ manifests an inverse linear dependency of temperature. The dimensionless variables are mentioned below in order to acquire the similarity solution:

$$
\mu=\frac{\mu_{\infty}}{1+\gamma\left(T-T_{\infty}\right)}
$$

Here $\left(\mu_{\infty}\right)$ represents ambient viscosity of the fluid and $\gamma$ denotes a constant. When we increase the temperature, the viscosity of the liquids decreases $(\gamma<0)$ whereas the viscosity of air and other gases increases $(\gamma>0)$. Equation (7) may also be rewritten in the form as given below:

$$
\frac{1}{\mu}=\alpha\left(T-T_{e}\right) \text { where } T_{e}=T_{\infty}-\frac{1}{\gamma} \text { and } \alpha=\frac{\gamma}{\mu_{\infty}} .
$$

We presumed thermal conductivity that is dependent on the temperature is of the shape $k(T)=k_{\infty}\left(1+\frac{\varepsilon\left(T-T_{\infty}\right)}{\left(T_{w}-T_{\infty}\right)}\right)$, in which $K_{\infty}$ represents thermal conductivity at ambient. The suitable boundary conditions for the considered flow model are defined as: 


$$
\begin{aligned}
& \text { At } z=0: V_{r}=0, V_{\varphi}=0, V_{z}=-V_{0}, T=T_{w}, \\
& \text { as } z \rightarrow \infty: V_{r} \rightarrow 0, V_{\varphi} \rightarrow r \omega, T \rightarrow T_{\infty} .
\end{aligned}
$$

Note that the centrifugal force is balanced by the radial pressure gradient in the exterior flow. Mathematically, we can write it as:

$$
\frac{\partial p}{\partial r}=\rho r \omega^{2}
$$

\section{1: Similarity Transformation:}

Depending upon the scale of length $\sqrt{\nu_{\infty} / \omega}$, we write the similarity variable (too called dimensionless distance) as $\zeta=z\left(v_{\infty} / \omega\right)^{-\frac{1}{2}}$. As the scale of velocity is $\sqrt{v_{\infty} \omega}$ and scale of time is $\omega^{-1}$, we introduce the dimensionless constituents of velocity $(\mathrm{F}, \mathrm{G}, \mathrm{H}) \&$ profile of temperature $\boldsymbol{\theta}$ without dimensions as follows:

$$
F(\zeta)=\frac{V_{r}}{r \omega}, G(\zeta)=\frac{V_{\varphi}}{r \omega}, H(\zeta)=\frac{V_{z}}{\sqrt{v_{\infty} \omega}}, \theta(\zeta)=\frac{T-T_{\infty}}{T_{w}-T_{\infty}}
$$

By applying boundary layer approximations and then using formulas (10) in equations (1-5); we acquire:

\begin{tabular}{|c|c|}
\hline $2 F+H^{\prime}=\mathrm{O}$, & (11) \\
\hline$F^{\prime \prime}-\frac{1}{\theta-\theta_{e}} F^{\prime} \theta^{\prime}+\frac{\theta-\theta_{e}}{\theta_{e}} M F+\frac{\theta-\theta_{e}}{\theta_{e}}\left(F^{2}+H F^{\prime}-G^{2}+1\right)=0$ & \\
\hline$G^{\prime \prime}-\frac{1}{\theta-\theta_{e}} G^{\prime} \theta^{\prime}+\frac{\theta-\theta_{e}}{\theta_{e}} M G+\frac{\theta-\theta_{e}}{\theta_{e}}\left(2 F G+H G^{\prime}\right)=0$, & \\
\hline$H \theta^{\prime}-\left(\frac{1}{\operatorname{Pr}}\right)\left[(1+\varepsilon \theta) \theta^{\prime \prime}+\varepsilon \theta^{\prime 2}\right]-M E c\left(F^{2}+G^{2}\right)-Q \theta+\left(\frac{\theta_{e}}{\theta-\theta_{e}}\right) E c\left[F^{\prime 2}+G^{\prime 2}\right]=0$, & \\
\hline
\end{tabular}

and the boundary conditions are transformed into:

$$
\begin{aligned}
& H(\zeta)=-A, F(\zeta)=0, G(\zeta)=0, \theta(\zeta)=1, \text { as } \zeta \rightarrow 0 \\
& F(\zeta) \rightarrow 0, G(\zeta) \rightarrow 1, \theta(\zeta) \rightarrow 0 \text { as } \zeta \rightarrow \infty .
\end{aligned}
$$


In the above mentioned expressions (11-15), $A=\frac{V_{0}}{\sqrt{v_{\infty} \omega}}$ denotes the wall suction parameter, $\operatorname{Pr}=\frac{\mu_{\infty} c_{p}}{k_{\infty}}$ denotes the value of Prandtl number at the ambient, $E c=\frac{r^{2} \omega^{2}}{c_{p}\left(T_{w}-T_{\infty}\right)}$ is the Eckert number, $M=\frac{\sigma B_{0}^{2}}{\rho \omega}$ denotes the magnetic field parameter, $\theta_{e}=\frac{T_{e}-T_{\infty}}{T_{w}-T_{\infty}}=\frac{-1}{\gamma\left(T_{w}-T_{\infty}\right)}$ indicates the dimensional constant and $Q=\frac{Q^{*}}{\rho c_{P} \omega}$ represents the parameter of heat generation/absorption.

\section{2: Nusselt number and Skin friction component:}

We define skin friction parameter as given below:

$$
C_{f}=\frac{\sqrt{\tau_{r}^{2}+\tau_{\varphi}^{2}}}{\rho(r \omega)^{2}}
$$

Where $\tau_{\varphi}$ denotes the circumferential wall stress and $\tau_{r}$ represents radial wall stress that can be evaluated by utilizing the Newtonian formulas as:-

$$
\begin{gathered}
\tau_{r}=\mu\left(\frac{\partial V_{r}}{\partial z}+\frac{\partial V_{z}}{\partial r}\right)_{z=0}=r \omega \frac{\mu_{\infty}}{\gamma\left(T_{w}-T_{\infty}\right) \theta(0)+1} \sqrt{\frac{\omega}{v_{\infty}}} F^{\prime}(0) \\
\tau_{\varphi}=\mu\left(\frac{\partial V_{\varphi}}{\partial z}+\frac{\partial V_{z}}{\partial r}\right)_{z=0}=r \omega \frac{\mu_{\infty}}{\gamma\left(T_{w}-T_{\infty}\right) \theta(0)+1} \sqrt{\frac{\omega}{v_{\infty}}} G^{\prime}(0)
\end{gathered}
$$

By utilizing expressions (7 and 10) in expressions (16, $17 \& 18)$, we obtain:

$$
C_{f}=\operatorname{Re}_{r}^{-\frac{1}{2}} \frac{\theta_{e}}{\theta_{e}-\theta} \sqrt{F^{\prime}(\mathrm{O})^{2}+G^{\prime}(\mathrm{O})^{2}}
$$

Here $\operatorname{Re}_{r}=\frac{r \omega^{2}}{v_{\infty}}$ indicates the rotational Reynolds number. Additionally, we define the local nusselt number as follows:

$$
N u=\frac{L q_{w}}{k\left(T_{w}-T_{\infty}\right)}
$$

in which $L=\sqrt{\frac{v_{\infty}}{\omega}}$ denotes the length scale $\&_{q_{w}}=-k\left(\frac{\partial T}{\partial z}\right)_{z=0}$ represents the wall heat flux of the current research problem. By using formulas (10) in expression (20), we get: 


$$
N u=-\theta^{\prime}(0)
$$

\section{Numerical consequences and discussion:}

In this portion, heat transfer influences in a Bodewadt flow with joule heating, viscous dissipation, magnetic field and internal heat generation and absorption that are evaluated by taking variable properties of fluid are discussed. Using Adams Bashforth method, numerical computations are obtained for velocity constituents \& temperature profile for distinct values of the concerned parameters in the range $0.2 \leq \operatorname{Pr} \leq 5.0,1.7 \leq A \leq 6.7,0.1 \leq M \leq 1.2,-100 \leq \theta_{e} \leq 100$, $-0.9 \leq Q \leq 3.6,0 \leq E c \leq 1.2,0 \leq \varepsilon \leq 4.1$. The graphical illustration of velocity constituents $(\mathrm{F}, \mathrm{G}$, $\mathrm{H}$ ) and temperature profile ( $\boldsymbol{\theta}$ ) for a variety of suction strength parameter are illustrated in Figs. 2a-d. The impact of suction leads to betterment in the frigidity rate of wall at a vast scale that is beneficial in numerous technical processes. The direction of the axial flow is directed upward in the absenteeism of wall suction, no matter how much greater the quantity of roughness parameter may be. The direction of inward flow of radial velocity $\mathrm{F}$ as portrayed in Fig. 2a is diminished monotonically with an increment in the value of wall suction parameter A and this is escorted with a reduction of axial flow $\mathrm{H}$ as shown in Fig. 2c. However, the radial inward flow generated by the pressure gradient decelerates with an enhancement in the value of wall suction parameter A. The circumferential constituent of velocity $G$ remains constant away from the disk whereas it is decreased significantly close to the disk due to the viscous drag as illustrated in Fig. $2 \mathrm{~b}$.

(a)




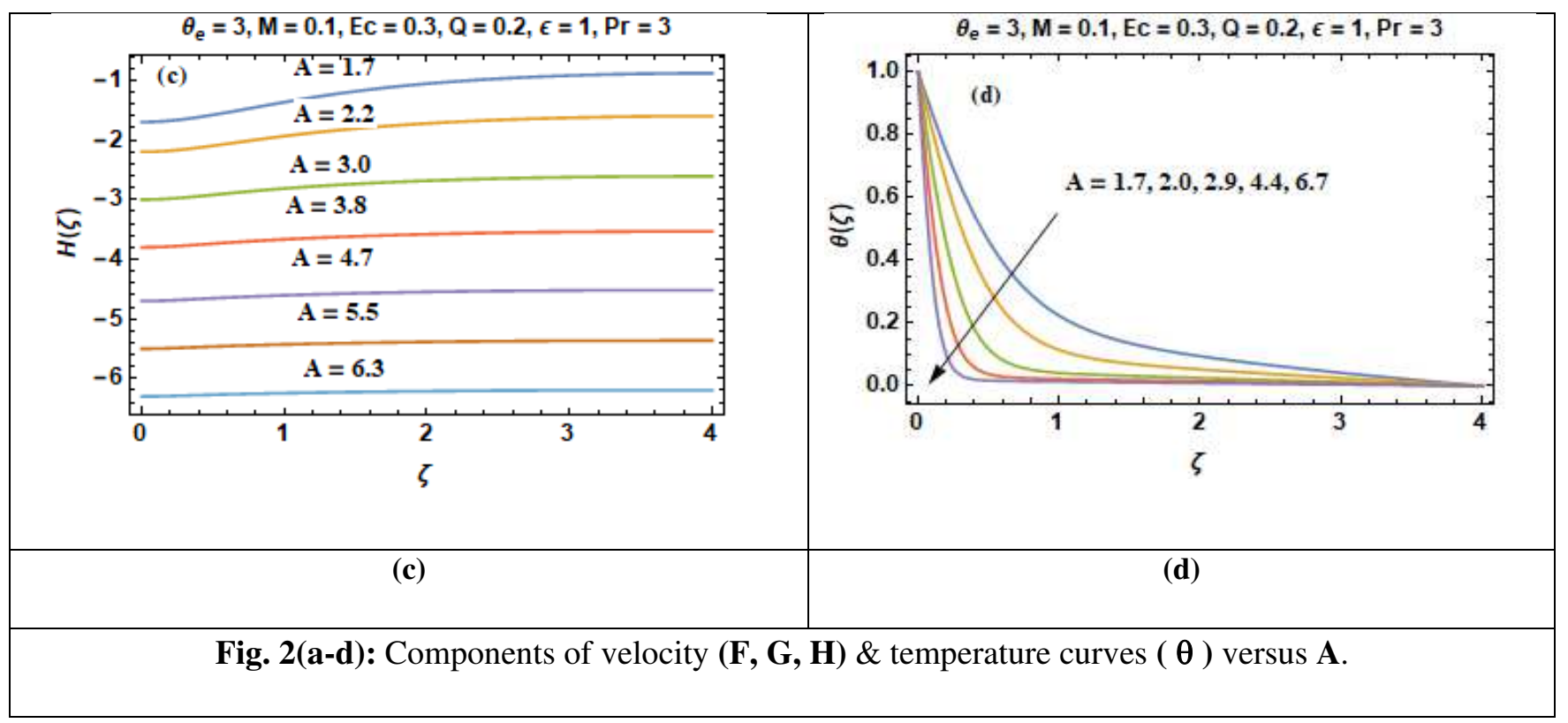

The axially independent radial pressure gradient compels the particles of the fluid close to the disk to move in the direction of rotational axis. For that reason, the direction of the axial flow in the Bodewadt flow is directed upwards as seen in Fig. 2c. The axially upward flow results into the non-physical solution of heat energy equation. Fig. 2c illustrates that axial component of velocity becomes constant when we applied an appropriate value of suction velocity. When we take $A=1$, the axial component of velocity $\mathrm{H}$ turns out to be negative revealing vertically downward locomotion of the fluid. All the three constituents of velocity manifest oscillations whose amplitude shrinks when axial distance increases. When $A \geq 1$, the direction of the axial flow is inverted such that the fluid instead moves towards the solid surface. Depth of heat penetration also decreases when suction velocity increases. The results of Fig. 2c depicts that when larger A is accounted than greater quantity of (cold) fluid is shifted in the direction of the disk. As a result, layer of thermal boundary is suppressed with an increment in the velocity of wall suction and boosts transfer of heat from the disk as portrayed in Fig. 2d. Lastly, the axially upward flow is a consequence of an unphysical solution to the problem of advection-diffusion. To overcome this physical incompatibility, we can reverse the direction of the axial flow through the application of sufficiently high suction velocity. Therefore, it can be stated that the effect of damping arising as a result of wall suction can overcome the absolute or convective type instabilities in bodewadt flow known from the published literature. 


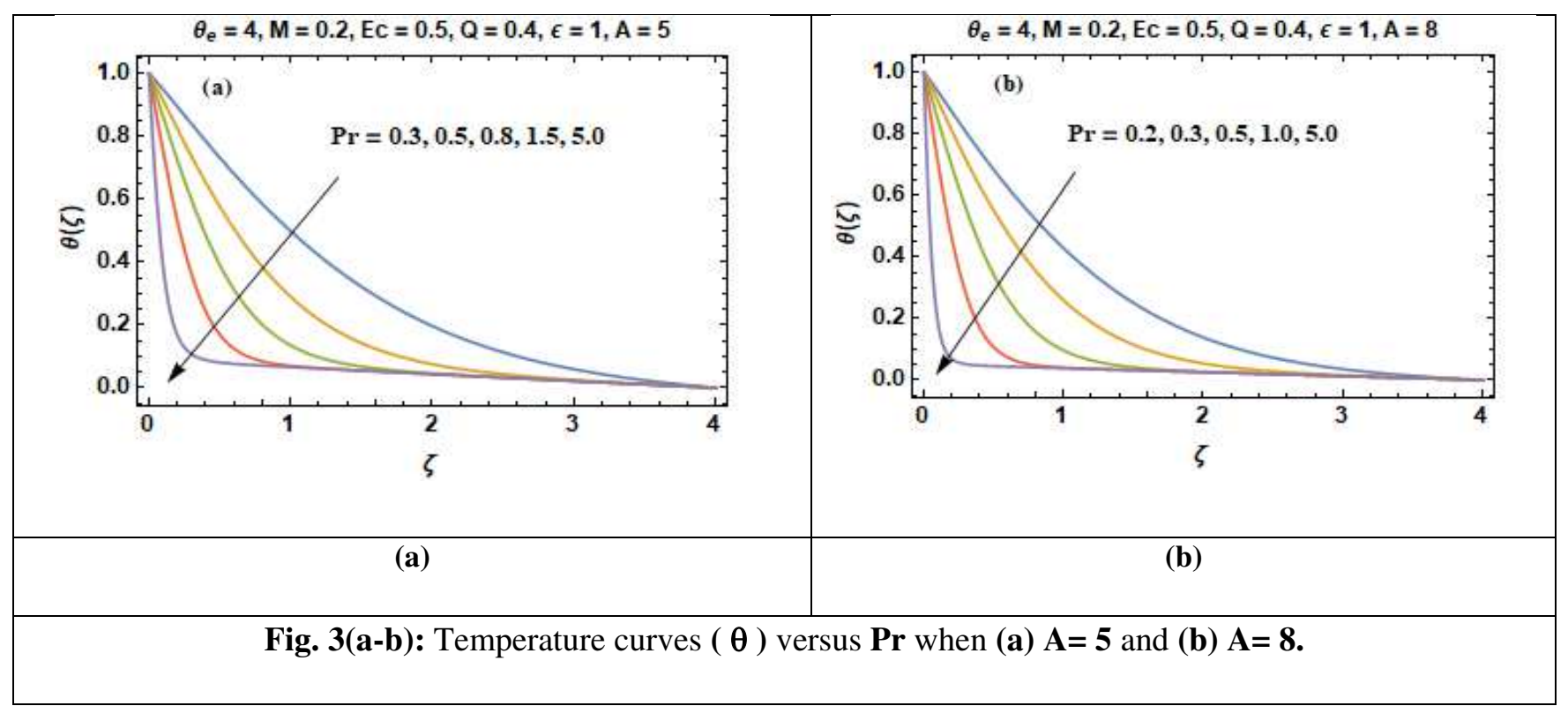

The variations of prandtl number ( $\mathrm{Pr})$ on dimensionless temperature profiles $\boldsymbol{\theta}$ in two cases $(\mathrm{A}=$ $5 \& \mathrm{~A}=8$ ) are depicted in Figs. 3a and 3b. It is suggested from the comparison of Figs. 3a and 3b that when velocity of wall suction increases than the deepness of heat penetration is much suppressed. It can be noted instantly that an enhancement in the values of prandtl number rises the temperature of the fluid in the vicinity of the disk. The graphs demonstrate that the thickness of layer of thermal boundary and fluid temperature decreases with an increment in the prandtl number on a fixed value of $\zeta$. The reason behind this is that prandtl number (Pr) is termed as fraction of momentum diffusion to thermal diffusion. When thermal diffusivity reduces, automatically the value of prandtl number (Pr) increases and fluid temperature decreases. In other words, temperature and prandtl number have an inverse relationship. Prandtl number controls the relative thickening of layer of thermal boundary and momentum boundary layer. However, the quantity of $\theta^{\prime}(0)$ increases considerably (in absolute sense) signaling a betterment in the rate of heat transition from the disk.

The influences of magnetic interaction parameter $(\mathrm{M})$ on the velocity constituents $(\mathrm{F}, \mathrm{G}, \mathrm{H})$ in $(r, \phi, z)$ directions and temperature curves $(\theta)$ can be visualized in Figs. 4a-d. The radial, circumferential and axial components of velocity are decreasing gradually with intensification of strength of magnetic field (M) as evinced in Figs. 4a, 4b \& 4c. The physics behind this is that an increase in the magnetic parameter (M) has the impact of damping the velocity profiles of fluid. This is because the direction of flow that is normal to the transverse magnetic field will result in a 
resistive force named as Lorentz force that is identical to the drag force which resist the fluid flow and as a consequence reduces the radial $(\mathrm{F})$, axial $(\mathrm{H})$ and tangential $(\mathrm{G})$ velocities. Behavior of temperature curves $(\theta)$ for non- identical values of magnetic field parameter $\mathrm{M}$ is illustrated in Fig. $4 \mathrm{~d}$. Contrary to the profiles of velocity, temperature $(\theta)$ enhances when we increase the value of M. This is due to the fact that bigger drag co-efficient on the surface owing to sturdy magnetic field offers resistance to the particles of fluid. As a consequence produces heat owing to which temperature $(\theta)$ enhances.

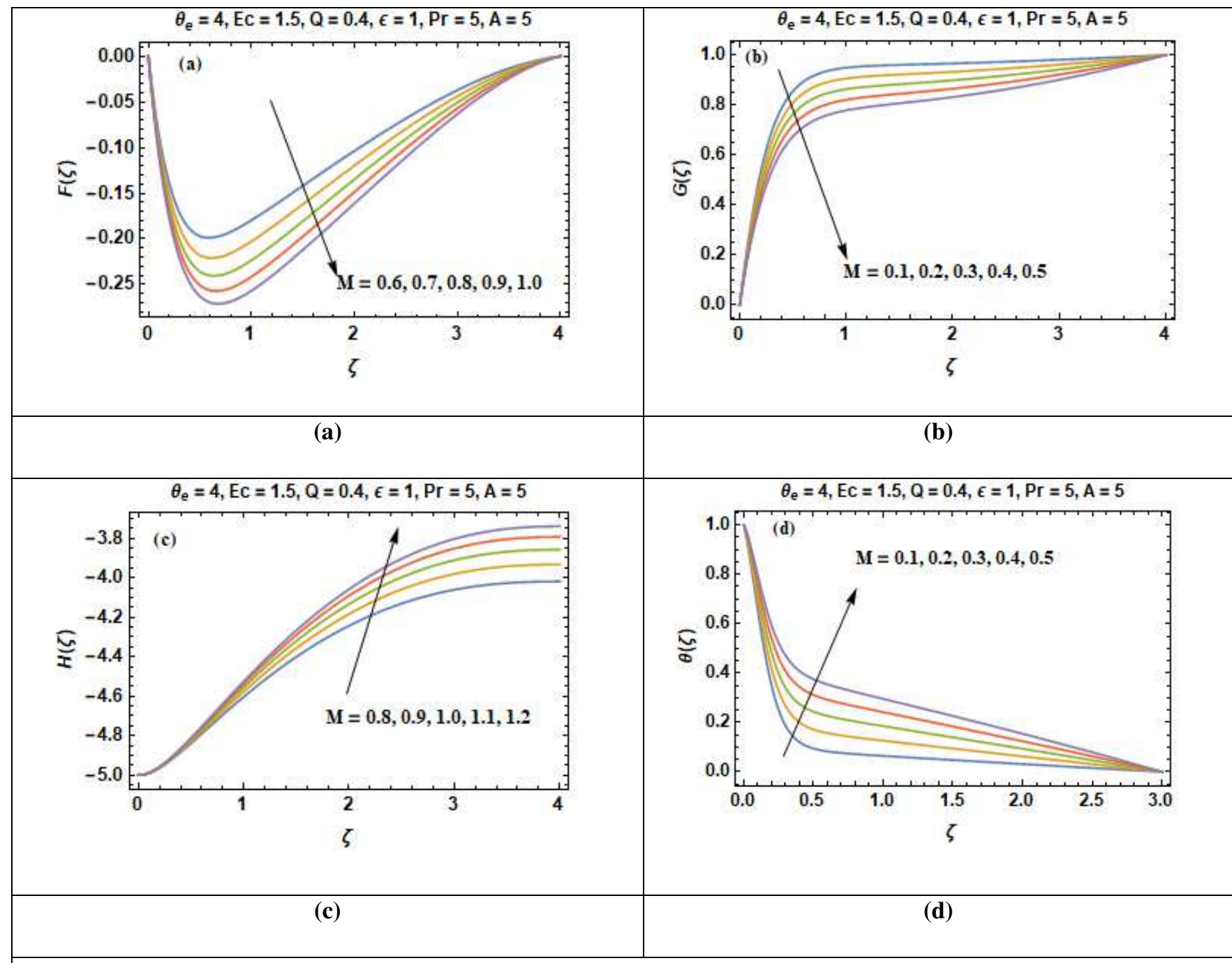

Fig. 4 (a-d): Components of velocity $(\mathbf{F}, \mathbf{G}, \mathbf{H})$ \& temperature profile ( $\boldsymbol{\theta}$ ) versus Magnetic field parameter $\mathbf{M}$.

Fig. 5a-d illustrates the change in velocity constituents $(F, G, H) \&$ temperature curve $(\theta)$ by changing the value of parameter $\left(\theta_{e}>0\right)$. In these figures, the value of prandtl number is kept persistent at $\operatorname{Pr}=1$ that is an adequate selection for air and numerous more gases. The value of 
variable viscosity parameter $\left(\theta_{e}\right)$ elasticities the significance of the quantity $1 / \gamma$ which is in direct proportion to the rate of dependence of viscosity on temperature of the fluid. When $\left(\theta_{e} \rightarrow \infty\right)$, the viscosity of the fluid becomes equivalent to the ambient viscosity whereas the viscosity of fluid becomes a sturdy function of temperature as $\left(\theta_{e} \rightarrow 0\right)$ when $\theta_{e}$ increases. Fig. $5 \mathrm{c}$ depicts that the axial velocity expedites in the downward direction as $\theta_{e}$ increases. As a consequence, this effect causes a reduction in the severity of the radial flow as illustrated in Fig. 5a. The value of entrainment velocity $\mathrm{H}(\infty)$ also increases indicating a growth in the fluid volume that is sucked in the direction of the disk. The circumferential component of velocity $\mathrm{G}$ accelerated in the upward direction when the value of $\theta_{e}$ increases as shown in Fig. 5b. As a result, the depth of heat penetration is (slightly) diminished and rate of heat transmission is augmented when $\theta_{e}$ is increased as illustrated in Fig. 5d.

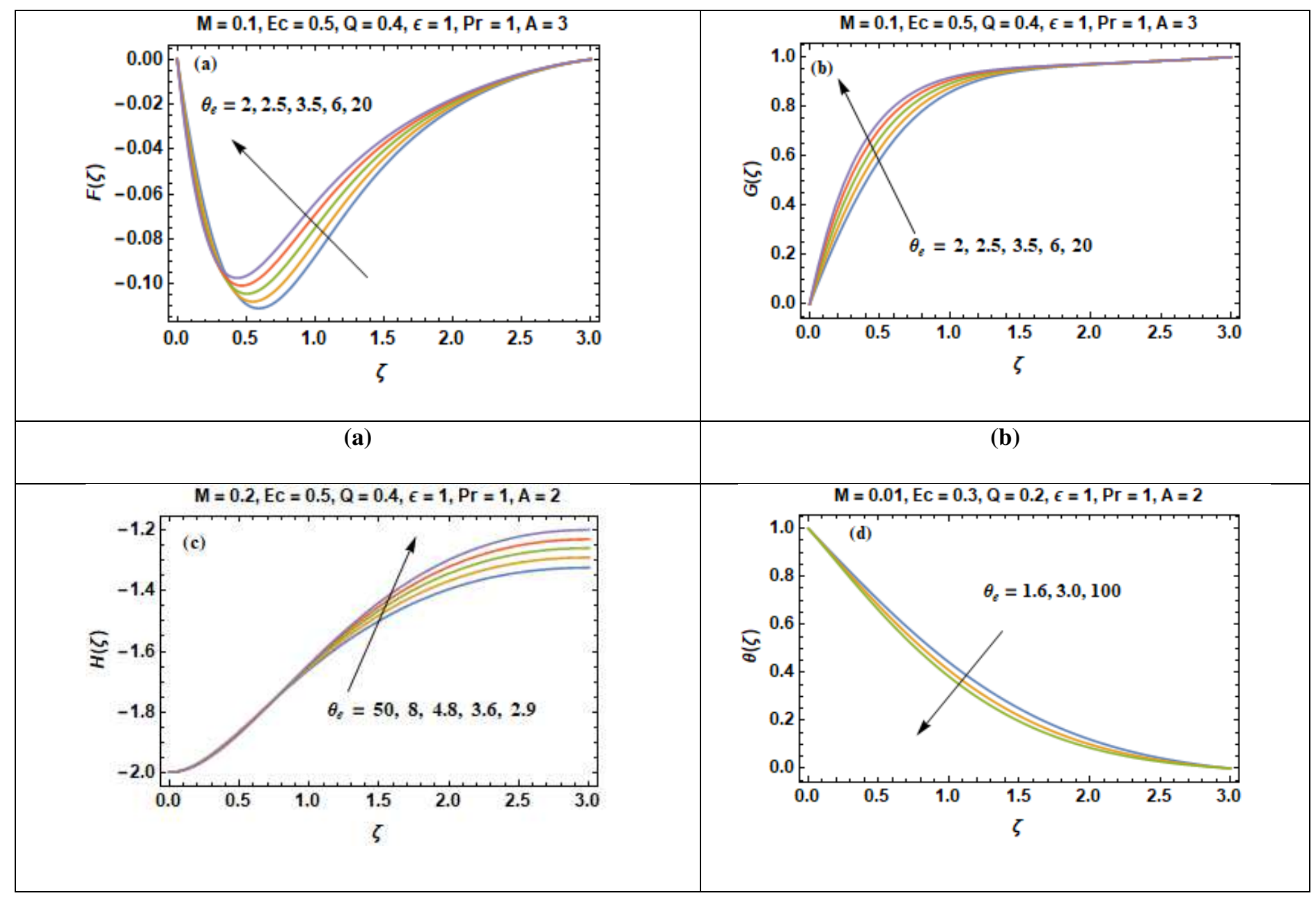


Fig. 5 (a-d): Components of velocity $(\mathbf{F}, \mathbf{G}, \mathbf{H}) \&$ temperature profile $(\boldsymbol{\theta})$ versus variable viscosity parameter $\theta_{e}>0$.

In Figs. 6a-d, we calculate velocity constituents and temperature curves for various values of variable viscosity parameter $\theta_{e}$ when $\left(\theta_{e}<0\right)$. In such situation, the viscosity of the fluid has an inverse relation with temperature. Different to the outcomes of Fig. 5c, the axial component of velocity decreases when we increase the value of $\theta_{e}$ that in results to the thickening of layer of thermal boundary as illustrated in Fig. 6d. Fig. 6b reveals that the tangential velocity accelerates in the upward direction when the value of $\theta_{e}$ increases.

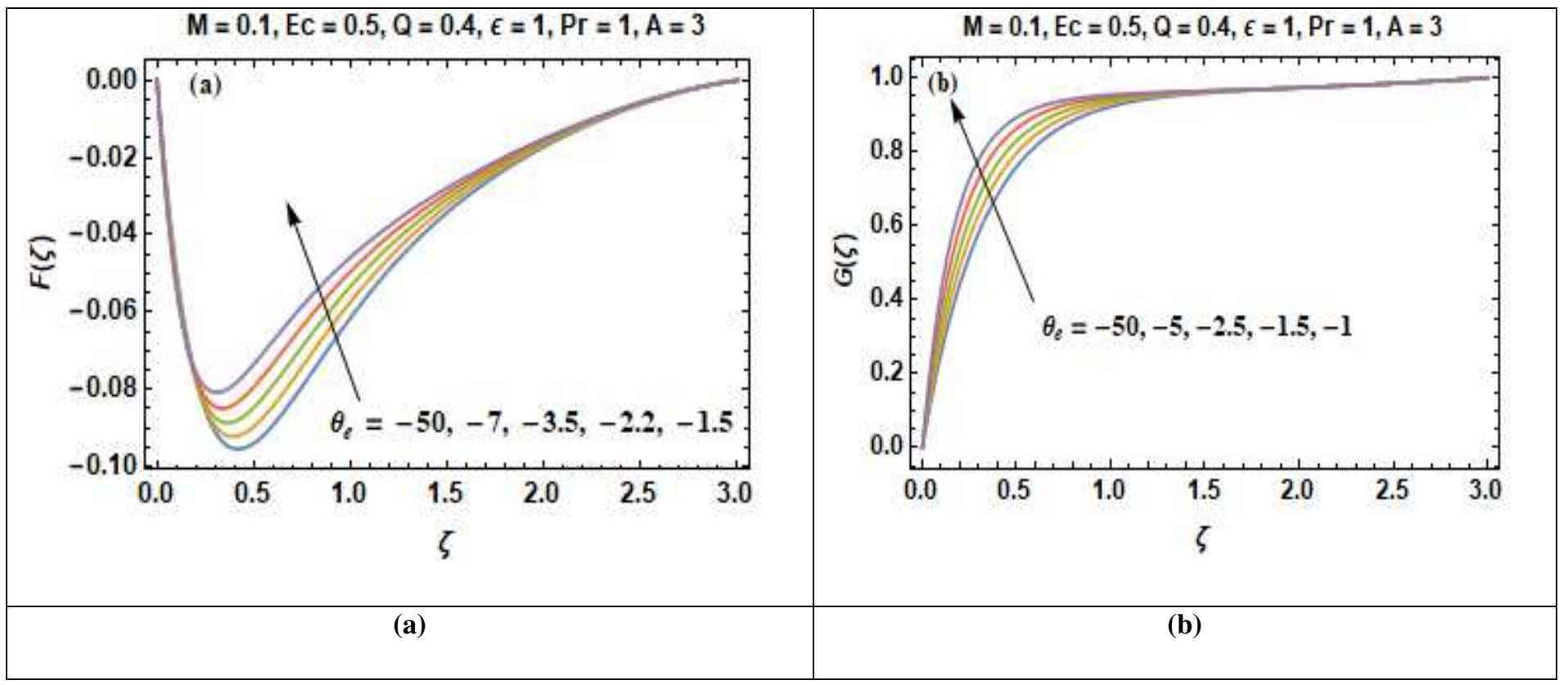




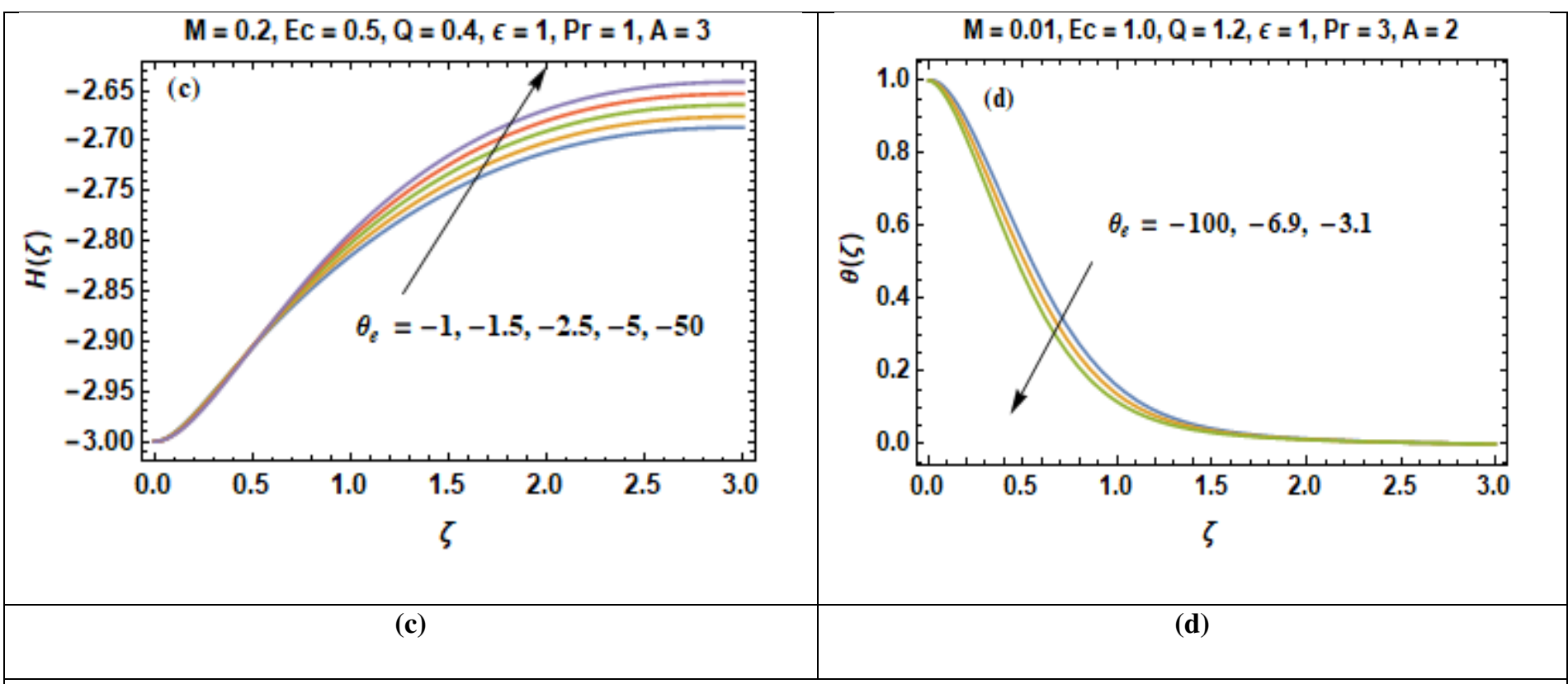

Fig. 6 (a-d): Components of velocity $(\mathbf{F}, \mathbf{G}, \mathbf{H}) \&$ temperature profile $(\boldsymbol{\theta})$ versus variable viscosity parameter $\theta_{e}<0$

The influences of heat generation and absorption parameter (Q) and Eckert number (Ec) are demonstrated in Figs. 7a-b. In Fig. 7a, negative values of parameter (Q) are representing the heat absorption $(\mathrm{Q}<0)$ and positive values are corresponding to heat generation $(\mathrm{Q}>0)$. It is obvious from the Fig. 7a that an enhancement in the heat generation produces an increase in the thickness of layer of thermal boundary whereas an increase in the heat absorption yields a decrease in the thickness of layer of thermal boundary. An increment in the absorption of heat implies that the heat is withdrawn by some means from the system. That is the reason that why an enhancement in the parameter of heat absorption results a reduction in the thickness of layer of thermal boundary and an increment in the rate of heat transfer. Contrary to this, an increment in the positive values manifest strong heat generation that enhances the fluid temperature in accordance with the definition of heat generation. Fig. $7 b$ portrays the influence of Eckert number on the temperature profile. An increase in the temperature is observed for greater values of viscous dissipation parameter $(\mathrm{Ec})$. An Eckert number $(\mathrm{Ec})$ is utilize to calculate the loss of energy during configuration of flow. It tells us the relationship between enthalpy difference and kinetic energy of liquid particles. For an augmentation in the values of Eckert number from 0 to 1.2, the mechanical energy of the fluid is transformed into thermal energy because of internal friction of molecules. Hence the temperature of the liquid increases. 


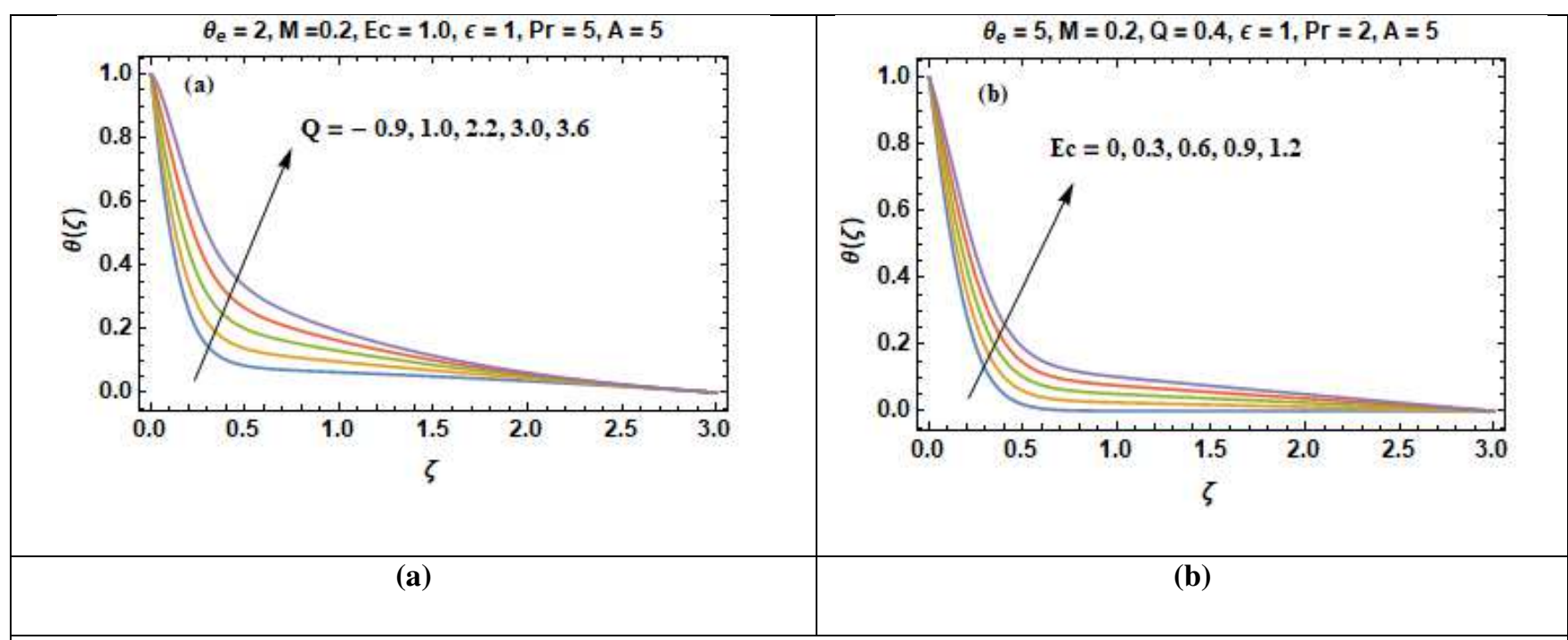

Fig.7 (a-b): Temperature curves ( $\boldsymbol{\theta}$ ) versus heat generation \& absorption parameter $\mathbf{Q}$ and Eckert number Ec.

Fig. 8a-d illustrates the change in velocity constituents and temperature curves for distinct values of parameter of variable thermal conductivity $(\mathcal{E})$. Fig. 8c shows that volumetric flow rate and axial velocity are decreasing functions of thermal conductivity parameter $(\mathcal{E})$. Such decrease in the axial flow intensity is indemnified by an increment in the inward radial velocity near the disk as illustrated in Fig. 8a. A cross over in the curves of velocity constituent $G$ shown in Fig. 8b revealing that azimuthal velocity $(\mathrm{G})$ increases away from the disk and decreases near the disk when parameter $(\mathcal{E})$ increases. Fig. $8 \mathrm{~d}$ shows that temperature profiles $(\theta)$ becomes thicker when we change the values of parameter $(\mathcal{E})$. It is because of this reason that thermal conductivity is in direct proportion with the parameter $(\mathcal{E})$. Hence an increment in the values of parameter ( $\mathcal{E}$ ) enhances the thermal condition of fluid that in result thickens the layer of thermal boundary. 


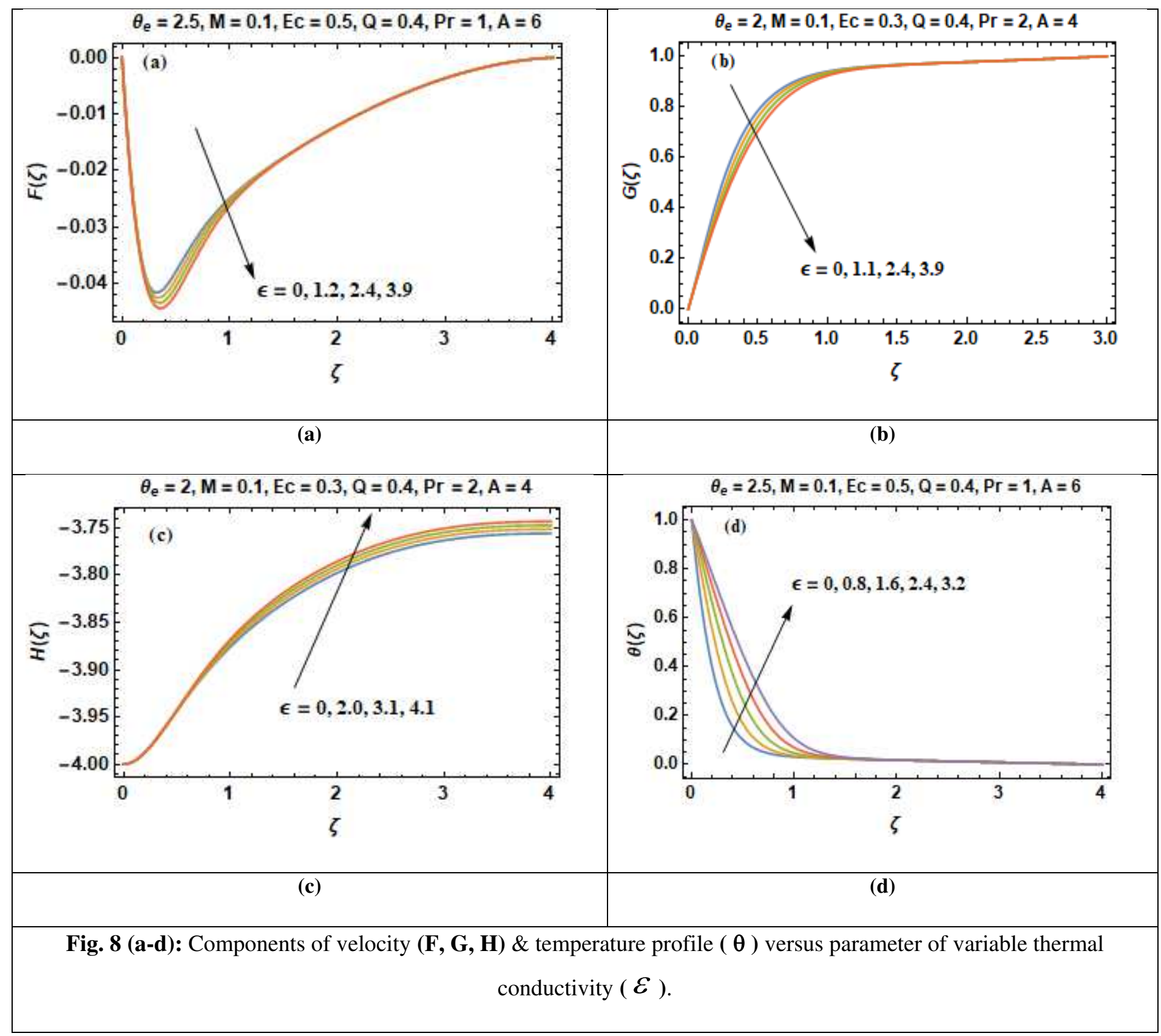

Results of skin friction parameter and Nusselt number for distinct values of emerging parameters are presented in Tables $1 \& 2$. Further, bar charts displayed the tabular data of skin friction parameter and nusselt number for different emerging parameters in Figs. (9-17). Table 1 demonstrate the impact of $A, \varepsilon, Q, E c, M$ and $\theta_{e}$ against skin friction parameter. Table 1. shows that value of skin friction parameter decreases when we increase the value of $\mathrm{A}$ and $\theta_{e}$ whereas skin friction parameter increases when we increase the value of $\varepsilon, Q, E c$ and $M$. Table 
2 highlighted the impact of $A, \varepsilon, Q, E c, M$ and $\theta_{e}$ against nusselt number. It is noticed that an increment in magnitude of A decays nusselt number while a direct trend is noticed for $\varepsilon, Q, E c, M$ and $\theta_{e}$.

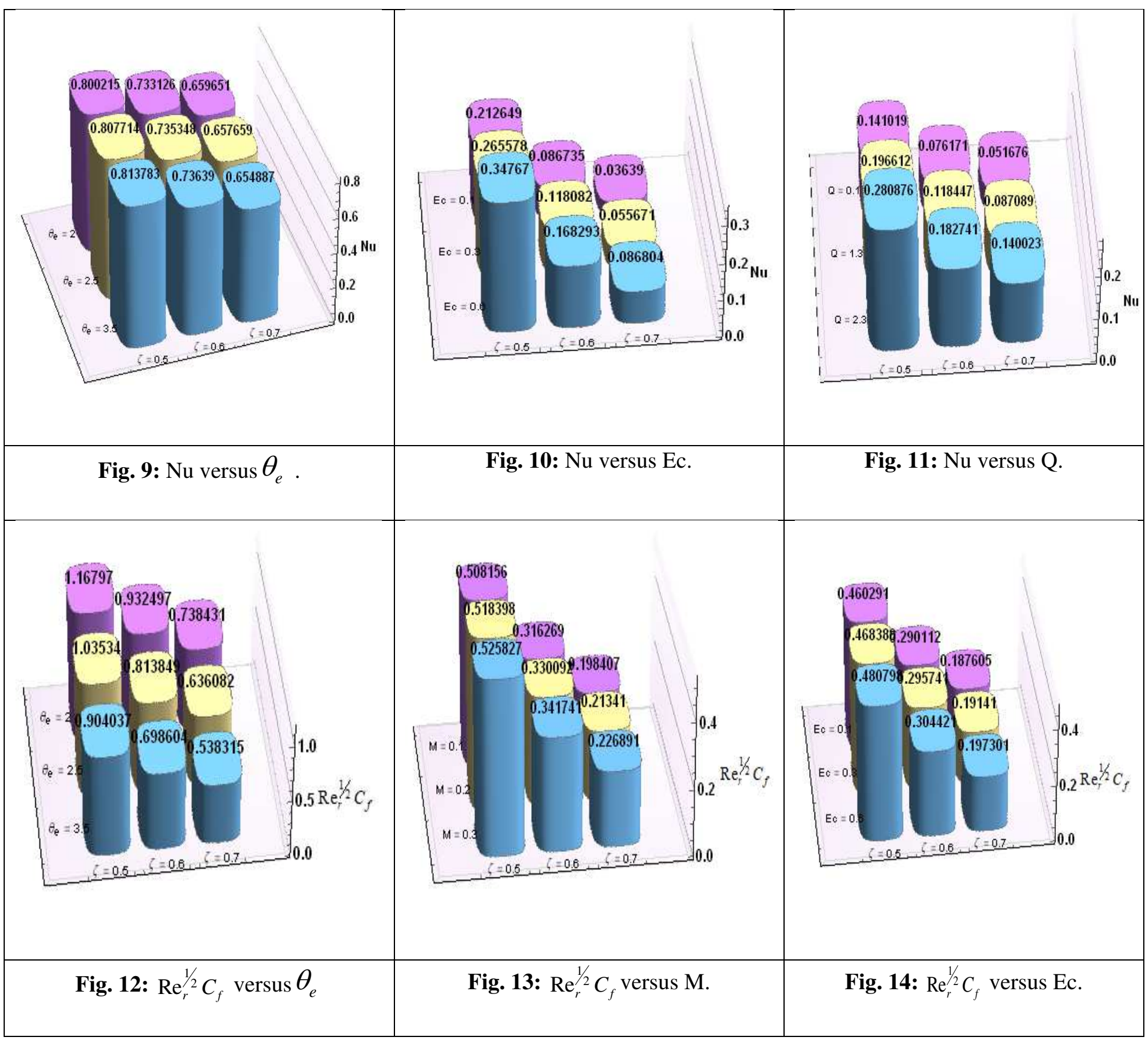




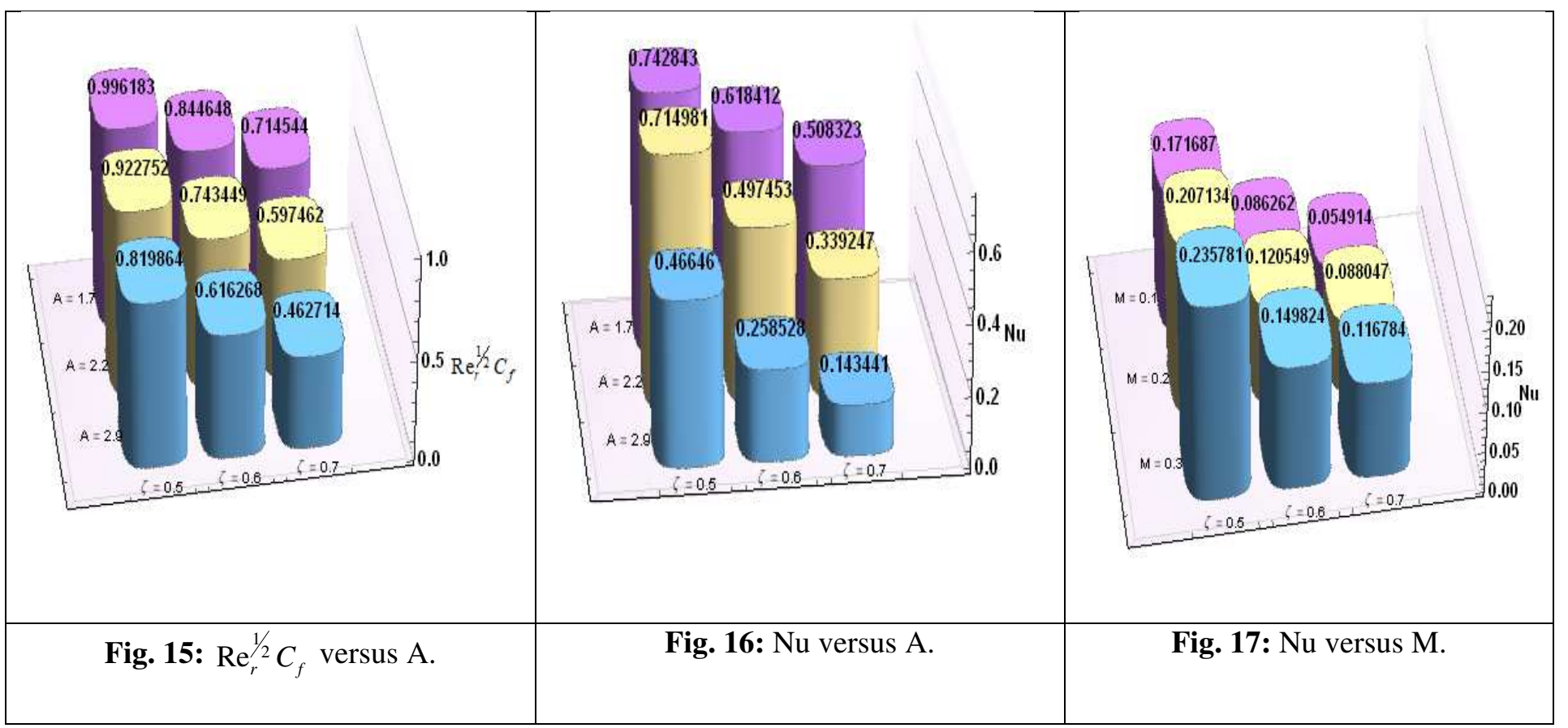

Table 1: Numerical values of Skin friction coefficient $\operatorname{Re}_{r}^{1 / 2} C_{f}$ against several physical quantities.

\begin{tabular}{|c|c|c|c|c|c|c|c|c|c|}
\hline $\mathrm{A}$ & $\mathrm{Pr}$ & $\varepsilon$ & $\mathrm{Q}$ & $\mathrm{Ec}$ & $\mathrm{M}$ & $\theta_{e}$ & $\operatorname{Re}_{r}^{1 / 2} C_{f}[0.5]$ & $\operatorname{Re}_{r}^{1 / 2} C_{f}[0.6]$ & $\operatorname{Re}_{r}^{1 / 2} C_{f}[0.7]$ \\
\hline 1.7 & 3.0 & 1.0 & 0.2 & 0.3 & 0.1 & 3.0 & 0.99618 & 0.84464 & 0.71454 \\
\hline 2.2 & 3.0 & 1.0 & 0.2 & 0.3 & 0.1 & 3.0 & 0.92275 & 0.74344 & 0.59746 \\
\hline 2.9 & 3.0 & 1.0 & 0.2 & 0.3 & 0.1 & 3.0 & 0.81986 & 0.61626 & 0.46271 \\
\hline 6.0 & 1.0 & 0.2 & 0.4 & 0.5 & 0.1 & 2.5 & 0.48244 & 0.27581 & 0.15946 \\
\hline 6.0 & 1.0 & 0.8 & 0.4 & 0.5 & 0.1 & 2.5 & 0.53268 & 0.30697 & 0.17785 \\
\hline 6.0 & 1.0 & 1.6 & 0.4 & 0.5 & 0.1 & 2.5 & 0.59541 & 0.34909 & 0.20411 \\
\hline 5.0 & 5.0 & 1.0 & 0.1 & 1.0 & 0.2 & 2.0 & 0.58866 & 0.37622 & 0.24477 \\
\hline 5.0 & 5.0 & 1.0 & 1.3 & 1.0 & 0.2 & 2.0 & 0.62915 & 0.40536 & 0.26512 \\
\hline 5.0 & 5.0 & 1.0 & 2.3 & 1.0 & 0.2 & 2.0 & 0.68613 & 0.44681 & 0.29429 \\
\hline 5.0 & 2.0 & 1.0 & 0.4 & 0.1 & 0.2 & 5.0 & 0.46029 & 0.29011 & 0.18760 \\
\hline 5.0 & 2.0 & 1.0 & 0.4 & 0.3 & 0.2 & 5.0 & 0.46838 & 0.29574 & 0.19141 \\
\hline 5.0 & 2.0 & 1.0 & 0.4 & 0.6 & 0.2 & 5.0 & 0.48079 & 0.30442 & 0.19730 \\
\hline
\end{tabular}




\begin{tabular}{|l|c|c|c|c|c|c|c|c|c|}
\hline 5.0 & 5.0 & 1.0 & 0.4 & 1.5 & 0.1 & 4.0 & 0.50815 & 0.31626 & 0.19840 \\
\hline 5.0 & 5.0 & 1.0 & 0.4 & 1.5 & 0.2 & 4.0 & 0.51839 & 0.33009 & 0.21341 \\
\hline 5.0 & 5.0 & 1.0 & 0.4 & 1.5 & 0.3 & 4.0 & 0.52582 & 0.34174 & 0.22689 \\
\hline 3.0 & 1.0 & 1.0 & 0.4 & 0.5 & 0.1 & 2.0 & 1.16797 & 0.93249 & 0.73843 \\
\hline 3.0 & 1.0 & 1.0 & 0.4 & 0.5 & 0.1 & 2.5 & 1.03534 & 0.81384 & 0.63608 \\
\hline 3.0 & 1.0 & 1.0 & 0.4 & 0.5 & 0.1 & 3.5 & 0.90403 & 0.69860 & 0.53831 \\
\hline
\end{tabular}

Table 2: Numerical values of Nusselt number $\mathrm{Nu}$ against several physical quantities.

\begin{tabular}{|c|c|c|c|c|c|c|c|c|c|}
\hline A & $\operatorname{Pr}$ & $\varepsilon$ & $\mathrm{Q}$ & Ec & $\mathrm{M}$ & $\theta_{e}$ & $\mathrm{Nu}[0.5]$ & $\mathrm{Nu}[0.6]$ & $\mathrm{Nu}[0.7]$ \\
\hline 1.7 & 3.0 & 1.0 & 0.2 & 0.3 & 0.1 & 3.0 & 0.74284 & 0.61841 & 0.50832 \\
\hline 2.2 & 3.0 & 1.0 & 0.2 & 0.3 & 0.1 & 3.0 & 0.71498 & 0.49745 & 0.33924 \\
\hline 2.9 & 3.0 & 1.0 & 0.2 & 0.3 & 0.1 & 3.0 & 0.46646 & 0.25852 & 0.14344 \\
\hline 6.0 & 1.0 & 0.2 & 0.4 & 0.5 & 0.1 & 2.5 & 0.47184 & 0.27443 & 0.15924 \\
\hline 6.0 & 1.0 & 0.8 & 0.4 & 0.5 & 0.1 & 2.5 & 0.70025 & 0.43585 & 0.26279 \\
\hline 6.0 & 1.0 & 1.6 & 0.4 & 0.5 & 0.1 & 2.5 & 0.95422 & 0.68563 & 0.46178 \\
\hline 5.0 & 5.0 & 1.0 & 0.1 & 1.0 & 0.2 & 2.0 & 0.14101 & 0.07617 & 0.05167 \\
\hline 5.0 & 5.0 & 1.0 & 1.3 & 1.0 & 0.2 & 2.0 & 0.19661 & 0.11844 & 0.08708 \\
\hline 5.0 & 5.0 & 1.0 & 2.3 & 1.0 & 0.2 & 2.0 & 0.28087 & 0.18274 & 0.14002 \\
\hline 5.0 & 2.0 & 1.0 & 0.4 & 0.1 & 0.2 & 5.0 & 0.21264 & 0.08673 & 0.03639 \\
\hline 5.0 & 2.0 & 1.0 & 0.4 & 0.3 & 0.2 & 5.0 & 0.26557 & 0.11808 & 0.05567 \\
\hline 5.0 & 2.0 & 1.0 & 0.4 & 0.6 & 0.2 & 5.0 & 0.34767 & 0.16829 & 0.08680 \\
\hline 5.0 & 5.0 & 1.0 & 0.4 & 1.5 & 0.1 & 4.0 & 0.17168 & 0.08626 & 0.05491 \\
\hline 5.0 & 5.0 & 1.0 & 0.4 & 1.5 & 0.2 & 4.0 & 0.20713 & 0.12054 & 0.08804 \\
\hline 5.0 & 5.0 & 1.0 & 0.4 & 1.5 & 0.3 & 4.0 & 0.23578 & 0.14982 & 0.11678 \\
\hline 3.0 & 1.0 & 1.0 & 0.4 & 0.5 & 0.1 & 2.0 & 0.80021 & 0.73312 & 0.65965 \\
\hline 3.0 & 1.0 & 1.0 & 0.4 & 0.5 & 0.1 & 2.5 & 0.80771 & 0.73534 & 0.65765 \\
\hline 3.0 & 1.0 & 1.0 & 0.4 & 0.5 & 0.1 & 3.5 & 0.81378 & 0.73639 & 0.65488 \\
\hline
\end{tabular}




\section{Concluding remarks:}

Impacts of heat transfer in a Bodewadt flow along with the consequences of viscous dissipation, heat generation/absorption, and magnetic field, joule heating and variable properties of the fluid are described numerically. The consequence of the current problem demonstrated that appropriate amount of wall suction is essential to restore well matched solutions of thermal energy equation physically. The key points of the current effort are appended as follows:

- Impact of wall suction has propensity to increase the heat transfer rate from the solid surface. Furthermore, charge of heat transfer seems to grow when viscosity approaches a constant value.

- Boundary layer is substantially thinned in Bodewadt's flow owing to the insertion of wall suction. All constituents of velocity \& temperature are diminishing functions of variable viscosity parameter $\theta_{e}$. Moreover, when higher $\theta_{e}$ is employed than the transformation in solution profiles with an increment in suction decreases.

- When parameter of variable thermal conductivity $\varepsilon$ becomes greater, than deterioration in rate of heat transfer is observed.

- The magnetic field (M) shows the opposite impact on velocity profile which means the velocity of the fluid diminishes with an increment in the value of $\mathrm{M}$. Reason is that the Lorentz forces are against the fluid flow. The temperature profiles improves with an increment in magnetic field.

- Opposite behavior of heat generation/absorption effects is observed over profile of temperature.

Data Availability Statement: Not applicable

Conflict of Interest: The authors declare no conflict of interest.

\section{References:}

[1] T. Von Karman, Uber laminare and turbulente Reibung, ZAMM - J. Appl. Math. Mech. / Zeitschrift fur Angewandte Mathematik und Mechanik, 1 (1921) 233-252. 
[2] W. G. Cochran, The flow due to a rotating disc, Mathematical Proceedings of the Cambridge Philosophical Society, 30 (1934) 365-375.

[3] J. A. D. Ackroyd, On the steady flow produced by a rotating disc with either surface suction or injection, Journal of Engineering Mathematics, 12 (1978) 207-220.

[4] M. Tabassum, M. Mustafa, A numerical treatment for partial slip flow and heat transfer of nonNewtonian Reiner-Rivlin fluid due to rotating disk, International Journal of Heat and Mass Transfer, 123 (2018) 979-987.

[5] G. K. Batchelor, Note on a class of solutions of the Navier-Stokes equations representing steady rotationally-symmetric flow, The Quarterly Journal of Mechanics and Applied Mathematics, 4 (1951) 29-41.

[6] M. H. Rogers, G. N. Lance, The rotationally symmetric flow of a viscous fluid in the presence of an infinite rotating disk, Journal of Fluid Mechanics, 7 (1960) 617-631.

[7] M. Turkyilmazoglu, Latitudinally deforming rotating sphere, Applied Mathematical Modeling, 71 (2019) 1-11.

[8] M. Turkyilmazoglu, Direct contact melting due to a permeable rotating disk, Physics of Fluids, 31 (2019) 023603.

[9] A. H. Nagoor, E. S. Alaidarous, M. T. Sabir, M. Shoaib, M. A. Z. Raja, Numerical treatment for three-dimensional rotating flow of carbon nanotubes with Darcy-Forchheimer medium by the Lobatto IIIA technique, AIP Advances, 10 (2020) 025016.

[10] M. I. Khan, T. Nasir, T. Hayat, N. B. Khan, A. Alsaedi, Binary chemical reaction with activation energy in rotating flow subject to nonlinear heat flux and heat source/sink, Journal of Computational Design and Engineering, 7 (2020) 279-286.

[11] U. T. Bodewadt, Die Dreh stromung uber festem Grund, ZAMM - J. Appl. Math. Mech. / Zeitschrift fur Angewandte Mathematik und Mechanik, 20 (1940) 241-253.

[12] B. Sahoo, R. A. V. Gorder, H. I. Andersson, Steady revolving flow and heat transfer of a nonNewtonian Reiner-Rivlin fluid, International Communications in Heat and Mass Transfer, 39 (2012) 336-342. 
[13] B. Sahoo, S. Abbasbandy, S. Poncet, A brief note on the computation of the Bödewadt flow with Navier slip boundary conditions, Computers \& Fluids, 90 (2014) 133-137.

[14] T. Rafiq, M. Mustafa, J. A. Khan, Numerical study of Bodewadt slip flow on a convectively heated porous disk in a nanofluid, Physica Scripta, 94 (2019) 095701.

[15] K. Muhammad, T. Hayat, A. Alsaedi, B. Ahmad, Numerical study of entropy production minimization in Bodewadt flow with carbon nanotubes, Physica A: Statistical Mechanics and its Applications, 550 (2020) 123966.

[16] V. K. Joshi, P. Ram, R. K. Sharma, D. Tripathi, Porosity effect on the boundary layer Bodewadt flow of a magnetic nanofluid in the presence of geothermal viscosity, The European Physical Journal Plus, 132 (2017) 254.

[17] M. Rahman, H. I. Andersson, On heat transfer in Bodewadt flow, International Journal of Heat and Mass Transfer, 112 (2017) 1057-1061.

[18] D. Mukherjee, B. Sahoo, The effects of Coriolis force and radial stretch on the convective instability characteristics of the Bodewadt flow, Proceedings of the Institution of Mechanical Engineers, Part C: Journal of Mechanical Engineering Science, (2021) 095440622110071.

[19] T. Rafiq, M. M. Hashmi, Bodewadt Flow Over a Permeable Disk with HomogeneousHeterogeneous Reactions: A Numerical Study, Applied Sciences, 9 (2019) 4046.

[20] M. Mustafa, I. Pop, K. Naganthran, R. Nazar, Entropy generation analysis for radiative heat transfer to Bodewadt slip flow subject to strong wall suction, European Journal of Mechanics - B/ Fluids, 72 (2018) 179-188.

[21] J. A. Khan, M. Mustafa, T. Hayat, F. Alzahrani, Numerical study for Bodewadt flow of water based nanofluid over a deformable disk: Buongiorno model, Indian Journal of Physics, 91 (2017) 527-533.

[22] G. K. Ramesh, E. H. Aly, S. A. Shehzad, F. M. Abbasi, Bödewadt flow and heat transfer of hybrid nanomaterial, International Journal of Ambient Energy, (2020) 1-9, https://doi.org/10.1080/01430750.2020.1818127. 
[23] P. Ram, I. Pop, V. K. Joshi, C. S. K. Raju, V. Kumar, Polarization force and geothermal viscosity driven unsteady Bödewadt transport phenomenon over a ferrofluid saturated disk, Physica Scripta, 96 (2020) 015202.

[24] M. Awais, M. Bibi, M. A. Z. Raja, S. E. Awan, M. Y. Malik, Intelligent numerical computing paradigm for heat transfer effects in a Bodewadt flow, Surfaces and Interfaces, 26 (2021) 101321.

[25] M. Mustafa, T. Rafiq, S. Hina, Bodewadt flow of Bingham fluid over a permeable disk with variable fluid properties: A numerical study, International Communications in Heat and Mass Transfer, 127 (2021) 105540.

[26] T. Rafiq, M. Mustafa, Bodewadt flow of Bingham fluids over a non-isothermal permeable disk with viscous dissipation effects, Alexandria Engineering Journal, 60 (2021) 2857-2864.

[27] Z. Abbas, M. Y. Rafiq, J. Hasnain, A. Nadeem, Thermally developed generalized Bodewadt flow containing nanoparticles over a rotating surface with slip condition, International Communications in Heat and Mass Transfer, 122 (2021) 105143.

[28] H. S. Takhar, S. Nitu, I. Pop, Boundary layer flow due to a moving plate: variable fluid properties, Acta Mechanica, 90 (1991) 37-42.

[29] T. Salahuddin, M. Arshad, N. Siddique, I. Tlili, Change in internal energy of viscoelastic fluid flow between two rotating parallel plates having variable fluid properties, Indian Journal of Physics, (2020) https://doi.org/10.1007/s12648-020-01833-0.

[30] Z. Ahmed, S. Nadeem, S. Saleem, R. Ellahi, Numerical study of unsteady flow and heat transfer CNT-based MHD nanofluid with variable viscosity over a permeable shrinking surface, International Journal of Numerical Methods for Heat \& Fluid Flow, 29 (2019) 4607-4623.

[31] T. Rafiq, M. Mustafa, M. A. Farooq, Modeling heat transfer in fluid flow near a decelerating rotating disk with variable fluid properties, International Communications in Heat and Mass Transfer, 116 (2020) 104673.

[32] N. Bachok, A. Ishak, I. Pop, Boundary Layer Flow and Heat Transfer with Variable Fluid Properties on a Moving Flat Plate in a Parallel Free Stream, Journal of Applied Mathematics, 2012 (2012) 1-10. 
[33] Z. Khan, H. U. Rasheed, T. Abbas, W. Khan, I. Khan, D. Baleanu, K. S. Nisar, Analysis of Eyring-Powell Fluid Flow Used as a Coating Material for Wire with Variable Viscosity Effect along with Thermal Radiation and Joule Heating, Crystals, 10 (2020) 168.

[34] M. A. Abbas, M. M. Bhatti, M. M. Rashidi, Heat transfer on Magnetohydrodynamic stagnation point flow through a porous shrinking/stretching sheet: A Numerical Study, Thermal Science, 24 (2020) 1335-1344.

[35] Z. Abdelmalek, U. Nazir, M. Nawaz, J. Alebraheem, A. Elmoasry, Double diffusion in Carreau liquid suspended with hybrid nanoparticles in the presence of heat generation and chemical reaction, International Communications in Heat and Mass Transfer, 119 (2020) 104932.

[36] A. Ali, F. Iqbal, D. N. K. Marwat, S. Asghar, M. Awais, Soret and Dufour effects between two rectangular plane walls with heat source/sink, Heat Transfer-Asian Research, 49 (2020) 614625 .

[37] W. Ibrahim, G. Gadisa, Finite element solution of nonlinear convective flow of Oldroyd-B fluid with Cattaneo-Christov heat flux model over nonlinear stretching sheet with heat generation or absorption, Propulsion and Power Research, 9 (2020) 304-315.

[38] J. Wang, M. I. Khan, W. A. Khan, S. Z. Abbas, M. I. Khan, Transportation of heat generation/absorption and radiative heat flux in homogeneous-heterogeneous catalytic reactions of non-Newtonian fluid (Oldroyd-B model), Computer Methods and Programs in Biomedicine, 189 (2020) 105310.

[39] S. Nasir, Z. Shah, S. Islam, W. Khan, E. Bonyah, M. Ayaz, A. Khan, Three dimensional Darcy-Forchheimer radiated flow of single and multiwall carbon nanotubes over a rotating stretchable disk with convective heat generation and absorption, AIP Advances, 9 (2019) 035031.

[40] M. Shoaib, M. A. Z. Raja, M. T. Sabir, M. Awais, S. Islam, Z. Shah, P. Kumam, Numerical analysis of 3-D MHD hybrid nanofluid over a rotational disk in presence of thermal radiation with Joule heating and viscous dissipation effects using Lobatto IIIA technique, Alexandria Engineering Journal, 60 (2021)3605-3619.

[41] M. Jawad, Z. Shah, A. Khan, W. Khan, P. Kumam, S. Islam, Entropy Generation and Heat Transfer Analysis in MHD Unsteady Rotating Flow for Aqueous Suspensions of Carbon 
Nanotubes with Nonlinear Thermal Radiation and Viscous Dissipation Effect, Entropy, 21 (2019) 492.

[42] M. I. Afridi, M. Qasim, I. Khan, I. Tlili, Entropy generation in MHD mixed convection stagnation-point flow in the presence of joule and frictional heating, Case studies in thermal engineering, 12 (2018) 292-300.

[43] H. Sithole, H. Mondal, P. Sibanda, Entopy generation in a second grade magnetohydrodynamic nanofluid flow over a convectively heated stretching sheet with nonlinear thermal radiation and viscous dissipation, Results in Physics, 9 (2018) 1077-1085.

[44] M. Zubair, Z. Shah, A. Dawar, S. Islam, P. Kumam, A. Khan, Entropy Generation Optimization in Squeezing Magnetohydrodynamics Flow of Casson Nanofluid with Viscous Dissipation and Joule Heating Effect, Entropy, 21 (2019) 747.

[45] L. A. Lund, Z. Omar, I. Khan, J. Raza, E. S. M. Sherif, A. H. Seikh, Magnetohydrodynamic (MHD) Flow of Micropolar Fluid with Effects of Viscous Dissipation and Joule Heating Over an Exponential Shrinking Sheet: Triple Solutions and Stability Analysis, Symmetry, 12 (2020) 142.

[46] S. A. Khan, T. Hayat, M. I. Khan, A. Alsaedi, Entropy Optimization in Magnetohydrodynamic Flow of Third-grade Nanofluid with Viscous Dissipation and Chemical Reaction, Iranian Journal of Science and Technology, Transactions A: Science, 43 (2019) 26792689.

[47] M. A. Sadiq, T. Hayat, Characterization of Marangoni Forced Convection in Casson Nanoliquid Flow with Joule Heating and Irreversibility, Entropy, 22 (2020) 433.

[48] R. Ahmed, N. Ali, S. U. Khan, I. Tlili, Numerical simulations for mixed convective hydromagnetic peristaltic flow in a curved channel with joule heating features, AIP Advances, 10 (2020) 075303.

[49] M. N. Tufail, M. Saleem, Q. A. Chaudhry, Two-parameter Lie convective Casson fluid scale study with MHD, joule heating and viscous dissipation influences, Proceedings of the Institution of Mechanical Engineers, Part C: Journal of Mechanical Engineering Science, (2020) https://doi.org/10.1177/0954406220964843. 
[50] M. Awais, S. E. Awan, M. A. Z. Raja, M. Shoaib, Effects of Gyro-Tactic Organisms in Bioconvective Nano-material with Heat Immersion, Stratification, and Viscous Dissipation, Arabian Journal for Science and Engineering, 46 (2021) 5907-5920.

[51] W. U. Khan, M. Awais, N. Parveen, A. Ali, S. E. Awan, M. Y. Malik, Y. He, Analytical Assessment of (A12O3-Ag/H2O) Hybrid Nanofluid Influenced by Induced Magnetic Field for Second Law Analysis with Mixed Convection, Viscous Dissipation and Heat Generation, Multidisciplinary Digital Publishing Institute, 11 (2021) 498.

[52] A. Ali, A. Noreen, S. Saleem, A. F. Aljohani, M. Awais, Heat transfer analysis of Cu-Al2O3 hybrid nanofluid with heat flux and viscous dissipation, Journal of Thermal Analysis and Calorimetry, 143 (2021) 2367-2377.

[53] Z. Shah, P. Kumam, W. Deebani, Radiative MHD Casson Nanofluid Flow with Activation energy and chemical reaction over past nonlinearly stretching surface through Entropy generation. Scientific Reports, 10 (2020), 4402.

[54] M. Awais, S. Bilal, Khalil-ur-Rehman, M. Y. Malik, Numerical investigation of MHD Prandtl melted fluid flow towards a cylindrical surface: comprehensive outcomes, Canadian Journal of Physics, 98 (2020) 223-232.

[55] M. I. Khan, S. A. Khan, T. Hayat, S. Qayyum, A. Alsaedi, Entropy generation analysis in MHD flow of viscous fluid by a curved stretching surface with cubic autocatalysis chemical reaction, The European Physical Journal Plus, 135 (2020) 1-17.

[56] N. A. Alreshidi, Z. Shah, A. Dawar, P. Kumam, M. Shutaywi, W. Watthayu, Brownian Motion and Thermophoresis Effects on MHD Three Dimensional Nanofluid Flow with Slip Conditions and Joule Dissipation Due to Porous Rotating Disk, Molecules, 25 (2020) 729.

[57] M. Bibi, M. Sohail, R. Naz, Theoretical analysis of MHD Carreau liquid over a heated rotating disk under Von-Karman transformations, Multidiscipline Modeling in Materials and Structures, 16 (2020) 390-408.

[58] A. Tanveer, S. Mahmood, T. Hayat, A. Alsaedi, On electroosmosis in peristaltic activity of MHD non-Newtonian fluid, Alexandria Engineering Journal, 60 (2021) 3369-3377. 
[59] M. Awais, S. E. Awan, M. A. Z. Raja, N. Parveen, W. U. Khan, M. Y. Malik, Y. He, Effects of Variable Transport Properties on Heat and Mass Transfer in MHD Bioconvective Nanofluid Rheology with Gyrotactic Microorganisms: Numerical Approach, Coatings, 11 (2021) 231.

[60] N. Parveen, M. Awais, S. E. Awan, W. U. Khan, Y. He, M. Y. Malik, Entropy Generation Analysis and Radiated Heat Transfer in MHD (Al2O3-Cu/Water) Hybrid Nanofluid Flow, Micromachines, 12 (2021) 887.

[61] T. Gul, M. Usman, I. Khan, S. Nasir, A. Saeed, A. Khan, M. Ishaq, Magneto hydrodynamic and dissipated nanofluid flow over an unsteady turning disk, Advances in Mechanical Engineering, 13 (2021)168781402110343.

[62] S. Islam, H. U. Rasheed, K. S. Nisar, N. A. Alshehri, M. Zakarya, Numerical Simulation of Heat Mass Transfer Effects on MHD Flow of Williamson Nanofluid by a Stretching Surface with Thermal Conductivity and Variable Thickness, Coatings, 11 (2021) 684.

[63] T. Rafiq, M. Mustafa, M. A. Farooq, Numerical assessment of Bödewadt flow and heat transfer over a permeable disk with variable fluid properties, Physica A: Statistical Mechanics and its Applications, 534 (2019) 122138. 